\title{
Evaluating the Dynamic Elastic Modulus of Concrete Using Shear-Wave Velocity Measurements
}

\author{
Byung Jae Lee, ${ }^{1}$ Seong-Hoon Kee, ${ }^{2}$ Taekeun $\mathrm{Oh},{ }^{3}$ and Yun-Yong Kim ${ }^{4}$ \\ ${ }^{1}$ R\&D Center, JNTINC Co. Ltd., 9 Hyundaikia-ro, 830 Beon-gil, Bibong-Myeon, Hwaseong, Gyeonggi-do 18284, Republic of Korea \\ ${ }^{2}$ Department of Architectural Engineering, Dong-A University, 37 Nakdong-Daero, 550 Beon-gil, Saha-gu, \\ Busan 49315, Republic of Korea \\ ${ }^{3}$ Department of Safety Engineering, Incheon National University, 119 Academy-ro, Yeonsu-gu, Incheon 22012, Republic of Korea \\ ${ }^{4}$ Department of Civil Engineering, Chungnam National University, 99 Daehak-ro, Yuseong-gu, Daejeon 34134, Republic of Korea
}

Correspondence should be addressed to Seong-Hoon Kee; shkee@dau.ac.kr

Received 4 January 2017; Revised 27 April 2017; Accepted 2 May 2017; Published 24 July 2017

Academic Editor: Giorgio Pia

Copyright (C) 2017 Byung Jae Lee et al. This is an open access article distributed under the Creative Commons Attribution License, which permits unrestricted use, distribution, and reproduction in any medium, provided the original work is properly cited.

\begin{abstract}
The objectives of this study are to investigate the relationship between static and dynamic elastic moduli determined using shear-wave velocity measurements and to demonstrate the practical potential of the shear-wave velocity method for in situ dynamic modulus evaluation. Three hundred 150 by $300 \mathrm{~mm}$ concrete cylinders were prepared from three different mixtures with target compressive strengths of 30,35 , and $40 \mathrm{MPa}$. Static and dynamic tests were performed at $4,7,14$, and 28 days to evaluate the compressive strength and the static and dynamic moduli of the cylinders. The results obtained from the shear-wave velocity measurements were compared with dynamic moduli obtained from standard test methods (P-wave velocity measurements according to ASTM C597/C597M-16 and fundamental longitudinal and transverse resonance tests according to ASTM C215-14). The shear-wave velocity measured from cylinders showed excellent repeatability with a coefficient of variation (COV) less than $1 \%$, which is as good as that of the standard test methods. The relationship between the dynamic elastic modulus based on shearwave velocity and the chord elastic modulus according to ASTM C469/C469M was established. Furthermore, the best-fit line for the shear-wave velocity was also demonstrated to be effective for estimating compressive strength using an empirical relationship between compressive strength and static elastic modulus.
\end{abstract}

\section{Introduction}

In the design of structures, the elastic modulus of concrete $\left(E_{c}\right)$ is a fundamental parameter in estimating the deformation of a structural element under service conditions. In practice, $E_{c}$ has been estimated from compressive strength based on the design code rather than on direct measurement. This practice could underestimate $E_{c}$ and demand higher compressive strength to achieve a desired $E_{c}$ than is actually required in structural design [1]. Furthermore, $E_{c}$ has been demonstrated to be an effective parameter for condition assessment of concrete in existing structures $[2,3]$. Destructive tests such as core extraction have been used widely to acquire accurate information on elastic properties of concrete. However, they are labor-intensive and time-consuming and cannot be applied ubiquitously over the entire area of the structure.

There are several nondestructive evaluation (NDE) methods to estimate elastic properties of concrete including ultrasonic pulse velocity measurements according to ASTM C597/C597M-16 [4] and resonance frequency tests according to ASTM C215-14 [5]. The elastic modulus determined by NDE methods is typically called the dynamic elastic modulus, which is generally greater than static elastic modulus measured in accordance with ASTM C469/C469M-14 [6]. Dynamic modulus has been assumed to be initial tangent modulus at zero stress determined in the standard test because only negligible stress is applied during ultrasonic pulse velocity (UPV) measurements and resonance frequency tests [7]. Philleo [8] also explained that the difference 
between dynamic and static moduli is based on the fact that the nonhomogeneous characteristics of concrete affect the two moduli in different ways. Moreover, the difference between the two moduli decreases as concrete strength increases: the dynamic elastic modulus is generally 20,30 , and $40 \%$ higher than the static elastic modulus for high-, medium-, and low-strength concrete, respectively [2]. Lydon and Balendran [9] proposed an empirical relationship as follows:

$$
E_{c}=0.83 E_{d}(\mathrm{GPa}) .
$$

The British testing standard BS8100 Part 2 [10] provides another empirical equation as follows:

$$
E_{c}=1.25 E_{d}-19(\mathrm{GPa}) .
$$

It is noteworthy that this equation does not apply to concrete containing more than $500 \mathrm{~kg}$ of cement per cubic meter of concrete or to lightweight aggregate concrete [7]. A more general relationship was proposed by Popovics [11] for both lightweight and normal density concrete, taking into account the effect of concrete density as follows:

$$
E_{c}=\frac{446.09 E_{d}^{1.4}}{\rho_{c}}(\mathrm{GPa})
$$

where $\rho_{c}$ is the density of the hardened concrete in a unit of $\mathrm{kg} / \mathrm{m}^{3}$.

The two standard NDE methods for evaluation of dynamic elastic modulus have advantages and limitations. The P-wave velocity method is convenient to use and has clear advantages over the resonance method in that the testing is not confined to regularly shaped laboratory specimens and results are not sensitive to inelastic effect [8]. P-waves move particles parallel to the direction of propagation and can propagate through media with enough lateral stiffness: they thus can propagate in solid, liquid, and gas media. Consequently, $\mathrm{P}$-wave velocity in porous materials is affected by the properties of three difference phases in the media. Dynamic elastic modulus determined by P-wave velocity measurements has been known to possess the characteristics of concrete, heterogeneous, and porous material, such as type of aggregate, water content, air voids, and porosity compared with the static elastic modulus. In addition, P-wave velocity values depend on confinement conditions in solid media: the $\mathrm{P}$-wave velocities in unbounded solid media $\left(C_{\mathrm{P}}\right)$, thin plates $\left(C_{c, \text { plate }}\right)$, and thin rods $\left(C_{c, \text { rod }}\right)$ are called constrained, partially constrained, and unconstrained compressive wave velocities, respectively, and are expressed as the following equations [12]:

$$
\begin{aligned}
C_{\mathrm{P}} & =\sqrt{\frac{E(1-v)}{\rho(1+v)(1-2 v)}}, \\
C_{c, \text { plate }} & =\sqrt{\frac{E}{\rho\left(1-v^{2}\right)}}, \\
C_{c, \text { rod }} & =\sqrt{\frac{E}{\rho} .}
\end{aligned}
$$

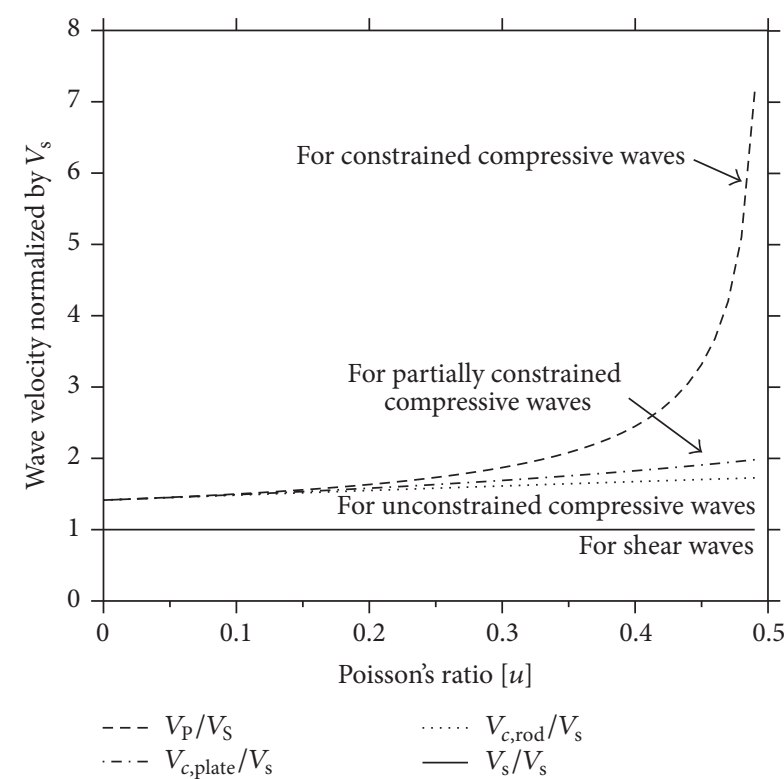

FIGURE 1: The variations of constrained, partially constrained, and unconstrained compressive waves and shear waves in elastic homogeneous and isotropic media with Poisson's ratio. The wave velocities are normalized by the $S$-wave velocity.

Figure 1 shows the variations of P-waves with Poisson's ratio for elastic homogeneous and isotropic media. Given Poisson's ratio, $\mathrm{P}$-wave velocity is in a range between unconstrained and constrained velocities [13]. P-wave velocity increases with increasing the degree of confinement, and the confinement effect increases as Poisson's ratio increases. In the field practice, however, it is sometimes not easy to evaluate accurate dynamic elastic moduli from P-wave velocity measurements because of difficulties in estimating the confinement effect in the field and the absence of theoretical or practical formula relating P-wave velocity and dynamic elastic modulus that takes into account the confinement effect. In this sense, some of previous researchers argue that the $\mathrm{P}$-wave velocity method is nonreliable and not recommended for estimating the dynamic elastic modulus of concrete $[1,7,14]$. In contrast, resonance frequency testing has been used widely to evaluate the dynamic elastic modulus of concrete, which is less sensitive than P-wave velocity. However, resonant frequency testing necessarily needs regularly shaped concrete specimens; thus, in situ application of this method is labor-intensive and timeconsuming and is inappropriate for general application over the entire area of a structure.

There has been some theoretical and experimental evidence demonstrating that the shear-wave measurement has potential to be an effective in situ NDE method for estimating solid stiffness of various cementitious materials (e.g., cement paste, mortar, and concrete). Theoretically, shear waves move particles perpendicular to the direction of propagation and thus can propagate through solid media with enough shear rigidity. Consequently, S-wave propagation is less sensitive to liquids or gases in porous materials. Previous researchers have demonstrated by experiments in the laboratory that 
TABLE 1: Mixture proportions of concrete.

\begin{tabular}{|c|c|c|c|c|c|c|c|c|c|c|c|}
\hline \multirow{3}{*}{ ID } & \multirow{3}{*}{ Cement type } & \multirow{3}{*}{$\mathrm{W} / \mathrm{B}$} & \multirow{3}{*}{ S/A } & \multicolumn{8}{|c|}{ Unit quantity $\left(\mathrm{kg} / \mathrm{m}^{3}\right)$} \\
\hline & & & & \multirow{2}{*}{$\mathrm{W}$} & \multirow{2}{*}{$\mathrm{C}$} & \multirow{2}{*}{ S } & \multirow{2}{*}{ G } & \multicolumn{2}{|c|}{ SCMs } & \multicolumn{2}{|c|}{ Chemical admixture } \\
\hline & & & & & & & & FA & SC & $\begin{array}{c}\mathrm{AE} \\
\text { (binder\%) }\end{array}$ & $\begin{array}{c}\text { SP } \\
\text { (binder\%) }\end{array}$ \\
\hline Mix 1 & \multirow{3}{*}{ Type I } & 0.45 & 0.46 & 259 & 121 & 777 & 934 & 58 & 69 & 0.9 & - \\
\hline Mix 2 & & 0.35 & 0.47 & 308 & 166 & 761 & 886 & 81 & 85 & - & 1 \\
\hline Mix 3 & & 0.3 & 0.46 & 357 & 165 & 714 & 868 & 94 & 99 & - & 1 \\
\hline
\end{tabular}

Note. SCMs: Supplementary cementitious materials, W: water, C: cement, S: sand, G: gravel, FA: fly ash, SC: slag cement, AE: air-entraining agent, and SP: superplasticizer.

S-waves are less sensitive to water and/or air content and an effective parameter for evaluating stiffness (or strength) gain of early-age cementitious materials. Voigt et al. [15] showed that the reflection of the $\mathrm{S}$-wave is closely related to the degree of interparticle bonding regardless of water content in cement paste. Zhu et al. [16] demonstrated experimentally that Swave velocity is not affected by air content in a range of $0.2 \%$ to $5.2 \%$ in cement paste, while P-wave velocity is too sensitive to air content. Liu et al. [17] successfully monitored setting and hardening processes of mortar and concrete using ultrasonic S-wave velocity in the laboratory and verified that S-wave velocity correlated well with penetration resistance in mortar regardless of test setup and water-to-cement ratio. Carette and Staquet [18] observed that S-wave velocity is more sensitive to the setting process of cement-based materials than $\mathrm{P}$-wave velocity. In addition, unlike $\mathrm{P}$-waves, $\mathrm{S}$-waves are theoretically not sensitive to confinement conditions of concrete [12]. In a homogeneous and isotropic medium, the $\mathrm{S}$-wave velocity is expressed as the following equation without regard to the confinement conditions [12]:

$$
C_{S}=\sqrt{\frac{E}{2 \rho(1+v)}} .
$$

Furthermore, some researchers have observed that S-wave velocity is a more stable parameter for evaluating compressive strength of hardened concrete than in P-wave velocity. An et al. [19]. observed that S-wave velocity is closely correlated with compressive strength without regard to the types of aggregate, curing age, and curing conditions. Ciancio and Helinski [20] demonstrated that the S-wave velocity measurement is effective in evaluating compressive strength of fiber reinforced shotcrete in field tests owing to its decreased sensitivity to the presence of pore water. In addition, Lencis et al. [21] observed that S-wave velocity is less sensitive to reinforcing steels in concrete than P-wave velocity. In the research, it was demonstrated that the influence of reinforcing steels is insignificant for S-wave velocity measurements in the indirect transmission method when concrete cover is at least $40 \mathrm{~mm}$, which is valid in most concrete structures in the field practice. Samokrutov et al. [22] demonstrated that using Swaves compared to $\mathrm{P}$-waves reduces the amount of backscattering and signal attenuation in the direction parallel to the propagating wave in hardened concrete. Recently, Lee and Oh [23] measured S-wave velocities using MIRA equipment that generates shear-wave tomography [24] and demonstrated the effectiveness of shear-wave measurements for condition assessment of reinforced and prestressed concrete slabs. In the study, it was demonstrated that S-wave velocity is statistically more stable than $\mathrm{P}$-wave velocity because of lower energy attenuation and less sensitivity of confinement effects. In summary, the S-wave velocity method has potential as an in situ NDE method for evaluating the elastic modulus and compressive strength of concrete. However, it is still difficult to draw a general conclusion due to a scarcity of experimental studies on evaluating the dynamic elastic modulus with the Swave velocity measurement.

The objectives of this study are to investigate the relationship between static and dynamic elastic moduli determined using S-wave velocity measurements and to demonstrate the practical potential of the S-wave velocity method for in situ dynamic modulus evaluation. In this study, three hundred 150 by $300 \mathrm{~mm}$ concrete cylinders were prepared from three different mixtures with target compressive strengths of 30 , 35 , and $40 \mathrm{MPa}$. Static and dynamic tests were performed at $4,7,14$, and 28 days to evaluate the compressive strength and the static and dynamic moduli of the cylinders. The results obtained from the $\mathrm{S}$-wave velocity measurements were compared with dynamic moduli obtained from standard test methods (P-wave velocity measurements in ASTM C597/C597M-16 and fundamental longitudinal and transverse resonance tests in ASTM C215-14).

\section{Experimental Program}

2.1. Materials and Preparation of Specimens. The concrete in this study consists of Type I Portland cement, river sand, crushed granite with a maximum size of $25 \mathrm{~mm}$, and supplementary cementitious materials (fly ash and slag cement). Three different water-to-binder ratios (W/B) of $0.3,0.35$, and 0.45 were used, which results in target compressive strengths of 40,35 , and $30 \mathrm{MPa}$, respectively. The three different concrete mixtures (hereafter referred to as mix 1, mix 2 , and mix 3) were prepared with ready-mixed concrete, and the proportions are summarized in Table 1.

Three hundred concrete cylinders were cast in 150 by $300 \mathrm{~mm}$ plastic molds in accordance with ASTM C31/C31M [25]. The cylinders were water-cured after being demolded on the next day. A series of static and dynamic modulus tests for 25 cylinders were conducted at different ages: 4, 7, 14, and 28 days. 


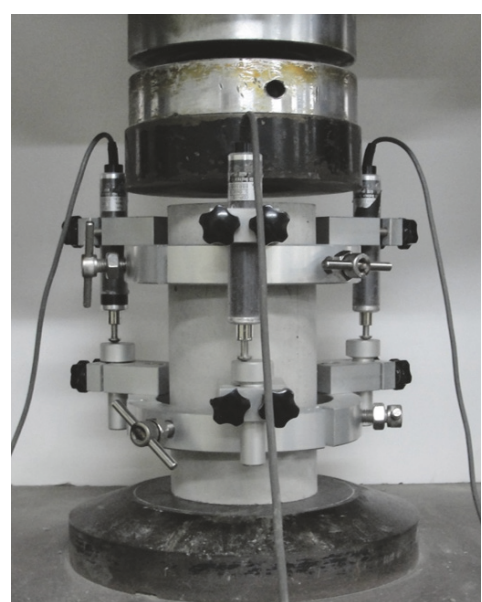

FIgURE 2: Test setup for measuring compressive strength and static elastic modulus of a concrete cylinder.

2.2. Static Tests for Compressive Strength and Elastic Modulus. The cylinders were ground at both ends before testing to remove any surface irregularities as well as to ensure that the ends were perpendicular to the sides of the specimen. Static elastic modulus and compressive strength of the cylinders were measured using a universal testing machine (UTM) with a capacity of $1000 \mathrm{kN}$ according to ASTM C469/C469M-14 [6] and ASTM C39/C39M-14 [26], respectively. Tests were performed at a loading rate of approximately $0.28 \mathrm{MPa} / \mathrm{s}$. Deformations were measured using three sets of linear voltage differential transducers attached to two fixed rings (Figure 2). The apparatus consisted of two aluminum rings with screws for attachment to the specimen. The spacing between screws on the top and bottom rings was $150 \mathrm{~mm}$. This served as a gauge length for calculating axial strain from the measured deformations. The static elastic modulus of concrete is defined as a chord modulus from the stress-strain curve, with a first point at a strain level of $0.00005\left(\varepsilon_{1}\right)$ and the second point at $40 \%$ of maximum stress $\left(f_{c}\right)$ as follows:

$$
E_{c}=\frac{0.4 f_{c}-\sigma\left(\varepsilon_{1}\right)}{\varepsilon\left(0.4 f_{c}\right)-\varepsilon_{1}} .
$$

It is of interest to compare dynamic elastic modulus and initial tangent modulus, which corresponds to a small strain and is calculated from the tangent drawn at the origin of the stress-strain curve [27]. Unfortunately, the measured stressstrain curve of cylinders in this study always showed certain fluctuations at very low strain, which posed considerable difficulties in consistent and reliable calculation of the initial tangent modulus. Instead, an initial chord modulus was defined from two points corresponding to strain levels of $0.000001\left(\varepsilon_{1}\right)$ and $0.00005\left(\varepsilon_{2}\right)$ as follows:

$$
E_{i}=\frac{\sigma\left(\varepsilon_{2}\right)-\sigma\left(\varepsilon_{1}\right)}{\varepsilon_{2}-\varepsilon_{1}} .
$$

Note that typical stress-strain curves of cylinders in this study show that stress increases almost linearly with strain at very low values of strain, that is, approximately 0.00005 . Therefore, the initial chord modulus is assumed to be equivalent to the initial tangent modulus of cylinders in this study.

2.3. P- and S-Wave Measurements for Estimating Dynamic Elastic Modulus. The S-wave velocity of concrete, $C_{S}$, was measured using the $\mathrm{P}$-wave velocity procedure described in ASTM C597/C597M-16 [4] with a pair of S-wave transducers (ACS T1802) that were connected to a pulser-receiver (Ultracon 170) (see Figure 3(a)). The source transducer was driven by a $200 \mathrm{~V}$ square pulse, generating a transverse ultrasonic pulse. The signals generated by the source transducer and measured by the receiving transducer were digitized at a sampling frequency of $10 \mathrm{MHz}$ using an NI-PXIe 6366 oscilloscope. Figure 4(a) shows typical impulse signal generated by a source transducer and an ultrasonic wave measured by a receiving transducer for the $\mathrm{S}$-wave velocity measurement. The arrival of the transient stress waves through cylinders was determined from the measured ultrasonic wave using the modified threshold method [28]. In this method, an approximate arrival time was first obtained using the conventional threshold method in the literature [29]. Next, an accurate arrival time was calculated by fitting a line to the single data. The intersection of the fitting line and the calculated zerosignal level defines the S-wave travel time. Finally, the S-wave velocity was calculated by dividing the length of cylinders $(L)$ over the travel time $(t)$ (i.e., $C_{\mathrm{s}}=L / t$ ). In this study, dynamic elastic modulus based on $C_{S}$ is determined by rearranging (7) as follows:

$$
E_{d, \mathrm{~S}}=\alpha_{\mathrm{S}} \rho C_{\mathrm{S}}{ }^{2}
$$

where $E_{d, \mathrm{~S}}$ is dynamic elastic modulus of the concrete specimen using S-wave velocity measurements, $\alpha_{\mathrm{S}}$ is constant dependent on Poisson's ratio $v$, that is, $2(1+v)$, and $\rho$ is mass density of concrete $\left(=m / \pi r^{2} L ; m, r\right.$, and $L$ are the mass, radius, and length of the cylinder, respectively, measured at testing day).

For comparison purposes, dynamic elastic moduli of concrete cylinders were also determined using standard NDE methods, including P-wave velocity and resonant frequency tests. In the P-wave velocity test, a longitudinal pulse of $52 \mathrm{kHz}$ is transmitted through the specimen, and the P-wave velocity of concrete, $C_{\mathrm{P}}$, is measured in accordance with ASTM C597/C597M-16 [4]. The test setup for P-wave velocity measurements was the same as that for the S-wave velocity measurements except for using a pair of P-wave transducers (MK 954). Figure 4(b) shows typical impulse signal generated by a source transducer and an ultrasonic wave measured by a receiving transducer for the $\mathrm{P}$-wave velocity measurement. The dynamic elastic modulus based on $C_{\mathrm{P}}$ is determined by rearranging (4) as follows:

$$
E_{d, \mathrm{P}}=\alpha_{\mathrm{P}} \rho C_{\mathrm{P}}^{2}
$$

where $E_{d, \mathrm{P}}$ is dynamic elastic modulus of the cylinder using the P-wave velocity measurements and $\alpha_{\mathrm{P}}$ is constant dependent on Poisson's ratio $v$, that is, $(1+v)(1-2 v)$ / $(1-v)$. 


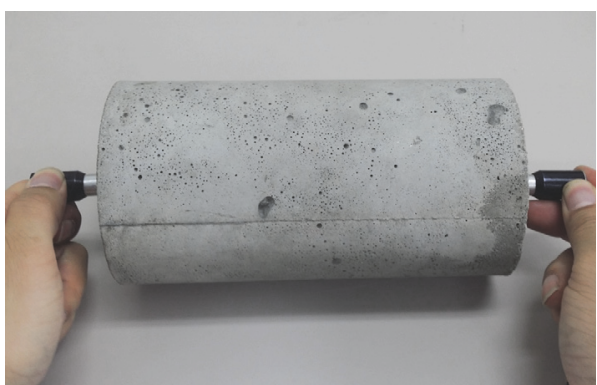

(a)

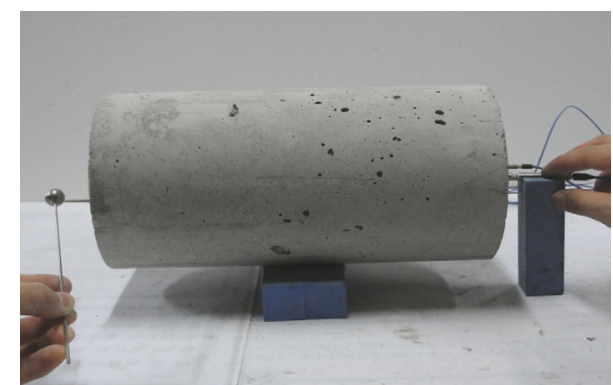

(b)

FIGURE 3: Testing configurations for (a) ultrasonic shear-wave velocity using a pair of S-wave transducers (ACS T1802) and (b) resonance frequency of concrete specimens.

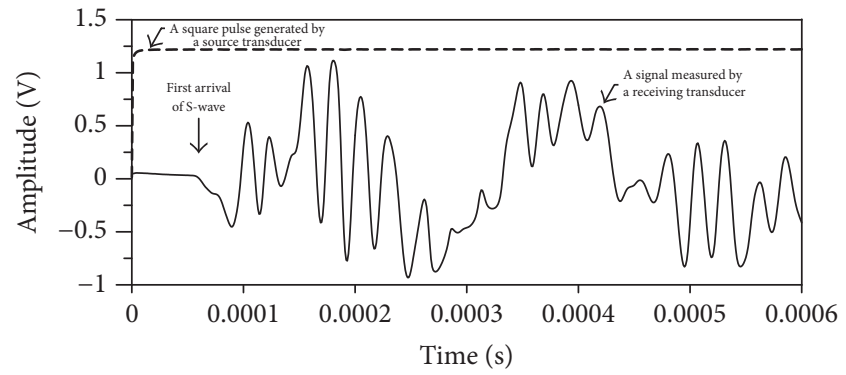

(a)

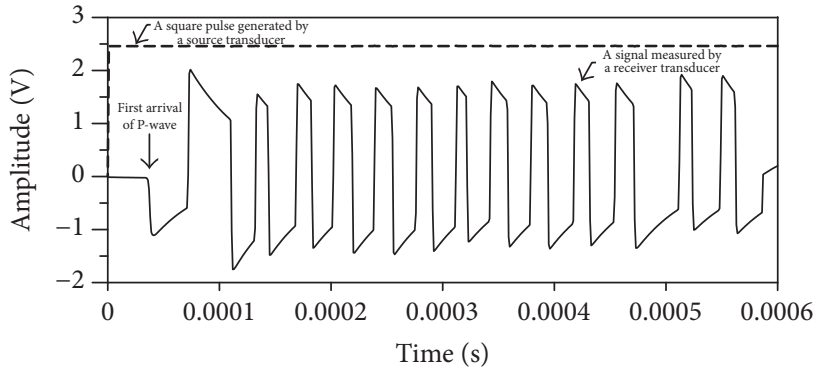

(b)

Figure 4: Typical impulse signals generated by a source transducer and ultrasonic waves obtained from ultrasonic pulse velocity tests for (a) $\mathrm{S}$-wave and (b) P-wave measurements.

\subsection{Resonance Frequency Measurements for Estimating Dy-} namic Elastic Modulus. Fundamental longitudinal and transverse resonant frequencies of the cylinders were measured to estimate dynamic elastic moduli in accordance with ASTM C215-14 [5] (see Figure 3(b)). A steel ball having a diameter of $10 \mathrm{~mm}$ was used as an impact source for generating incident stress waves in concrete specimens; the steel ball was effective for generating wideband frequency signals from very low to $20 \mathrm{kHz}$, covering the frequency range of resonant frequency tests in this study. The dynamic response of the concrete cylinder was measured by an accelerometer (PCB 353B16), with $\pm 5 \%$ frequency range of 1 to $10 \mathrm{kHz}$ and resonant frequency around $70 \mathrm{kHz}$, attached to the concrete specimen according to ASTM C215-14 [5]. The acquired signals using the accelerometer were stabilized using a signal conditioner (PCB 482C16) and digitized at a sampling frequency of $1 \mathrm{MHz}$ using an NI-PXIe 6366 oscilloscope. Resulting time signals were converted into the frequency domain using the FFT (fast Fourier transform) algorithm. Figure 5 shows typical spectral amplitude from the mix 2 concrete cylinders with ages of $4,7,14$, and 28. The resonant frequencies of the cylinders are manifested as dominant amplitudes in the amplitude spectrum. The most dominant frequency was regarded as the fundamental resonant frequency for longitudinal $f_{\mathrm{L}}$ and transverse $f_{\mathrm{T}}$ modes, and the frequency values were used to calculate dynamic elastic moduli of the cylinders as follows:

$$
E_{d, \mathrm{LR}}=\beta_{\mathrm{L}} m f_{\mathrm{L}}^{2}(\mathrm{~Pa}),
$$

$$
E_{d, \mathrm{TR}}=\beta_{\mathrm{T}} m f_{\mathrm{T}}^{2}(\mathrm{~Pa})
$$

where $E_{d, \mathrm{LR}}$ and $E_{d, \mathrm{TR}}$ are dynamic elastic moduli using longitudinal and transverse fundamental resonant frequencies, respectively; $\beta_{L}$ is a constant depending on the dimensions of the cylinder $=5.093\left(L / D^{2}\right) ; L$ and $D$ are the length and diameter of a cylinder, respectively; $\beta_{T}$ is a constant depending on dimensions and Poisson's ratio of cylinder $\left(=1.6067\left(L^{3} T / D^{4}\right)\right)$; and $T$ is a correction factor obtained from ASTM C215-14[5].

\section{Result and Discussion}

3.1. Experimental Variability of Static and Dynamic Tests. Experimental variability of the measured static and dynamic parameters is of interest when investigating the consistency and reliability of the test methods. Uncertainty of the average value of the in-place test results is a function of the standard deviation of the results and the number of tests. In this study, the coefficient of variation (COV, the standard deviation, $\sigma$, divided by the mean value, $\mu$, of a set of specimens) was used as a means of evaluating the experimental variability of the static and dynamic measurements of the concrete cylinders; outliers were detected by the modified $Z$-score method [30] and were removed in the statistical analysis. The statistical parameters ( $\mu$ and COV) of the accepted static and dynamic test results are summarized in Table 2. 
TABLE 2: Summary of statistical analysis.

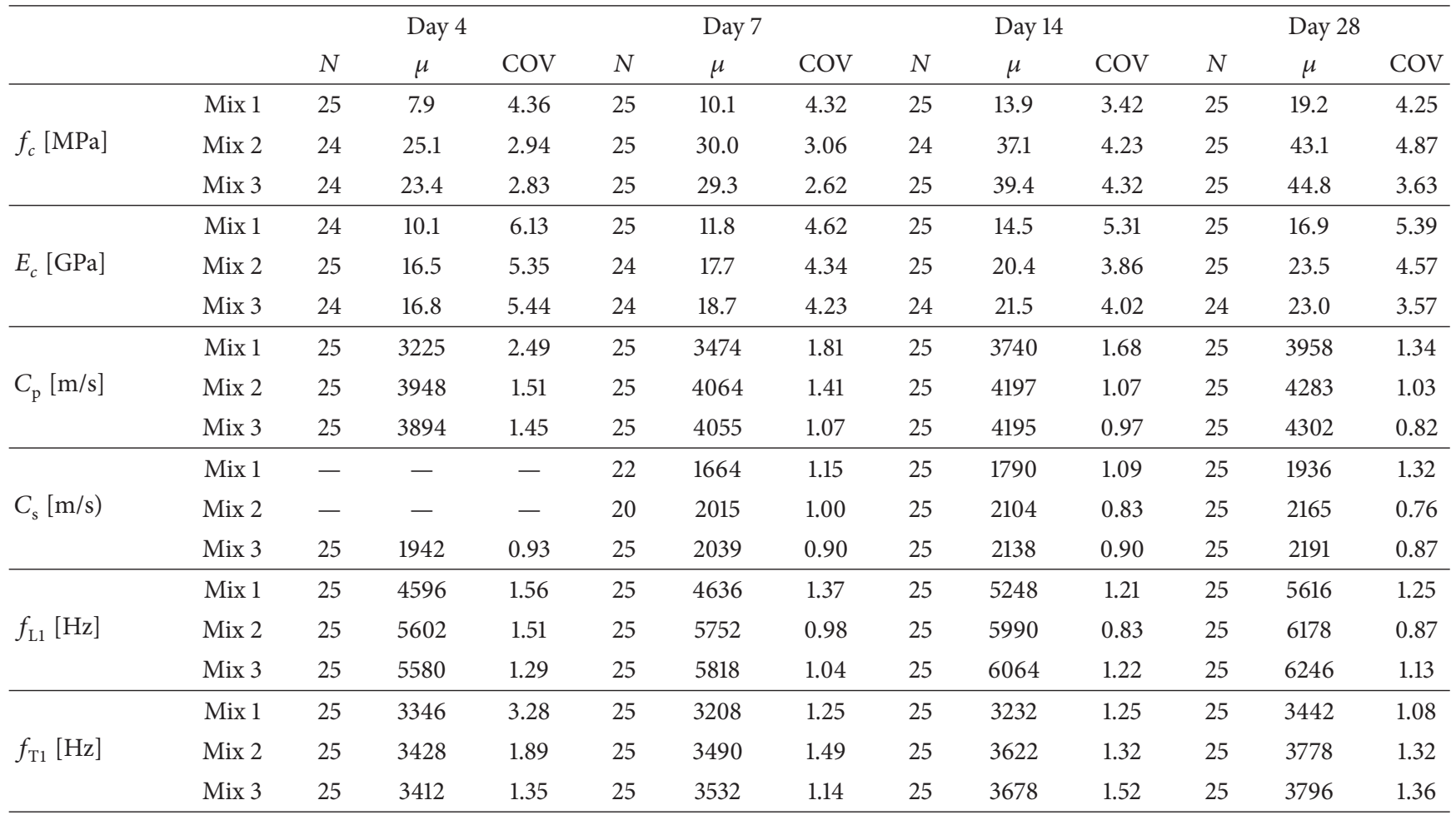

Note. $N=$ the number of accepted samples used for the statistical analyses; $\mu=$ average of samples; and COV $=$ coefficient of variable $(=\sigma / \mu \times 100[\%])$.

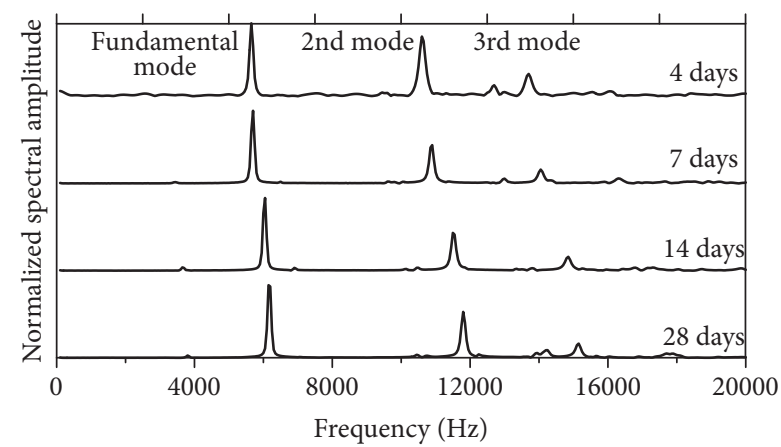

(a)

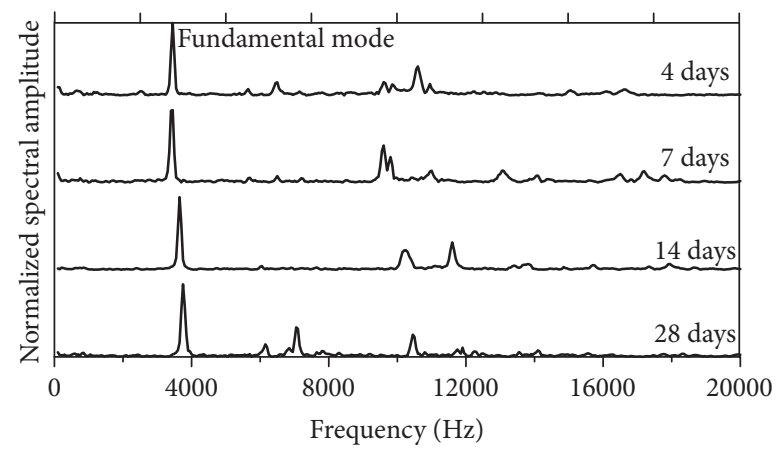

(b)

FIGURE 5: Typical spectral amplitude measured from the mix 2 concrete cylinders with ages of $4,7,14$, and 28 days using (a) longitudinal and (b) transverse resonance frequency tests.
The COV of the compressive strength of concrete $f_{c}$ ranges from $2.62 \%$ to $4.97 \%$ for concrete specimens with different mixture proportions and testing ages, which are between good $(4.0$ to 5.0$)$ and excellent $(<3.0)$ categories, according to ACI 214R [31]. The COV of the static elastic modulus $E_{c}$ ranges from $3.57 \%$ to $6.13 \%$. A slightly higher $\mathrm{COV}$ and more rejected observations in $E_{c}$ are mainly due to the fact that the measurement of $E_{c}$ involves more sources of variation than the measurement of $f_{c}$. The COVs of both $f_{c}$ and $E_{c}$ are reasonably consistent at the different ages of 4, 7,14 , and 28 days.

The COV of the P-wave velocity $\left(C_{\mathrm{P}}\right)$ ranges from $0.82 \%$ to $2.49 \%$, which is consistent with observations by ACI committee 228 [32]. Furthermore, the COV of the fundamental longitudinal $f_{\mathrm{L}}$ and transverse $f_{\mathrm{T}}$ frequencies ranges from $0.83 \%$ to $1.56 \%$ and from $1.08 \%$ to $3.28 \%$, respectively. No outlier was detected by the modified $Z$-score for the three data sets $C_{\mathrm{P}}, f_{\mathrm{L}}$, and $f_{\mathrm{T}}$. The low COVs and lack of detected outliers show the excellent consistency of $C_{\mathrm{P}}, f_{\mathrm{L}}$, and $f_{\mathrm{T}}$.

Furthermore, the COV of the accepted S-wave velocity $\left(C_{\mathrm{S}}\right)$ ranges from $0.76 \%$ to $1.32 \%$, which is comparable to that of $C_{\mathrm{P}}, f_{\mathrm{L}}$, or $f_{\mathrm{T}}$. This statistical result clearly shows that $\mathrm{S}$ wave velocity measurements have excellent consistency and could be a consistent and reliable test method in practice. However, in early-age concrete, accurate detection of the first arrival time of S-waves is often difficult because of the interference between direct P- and S-waves; even using Swave transducers, $\mathrm{P}$-wave components with low amplitude always appear along with the $\mathrm{S}$-wave components in the time 

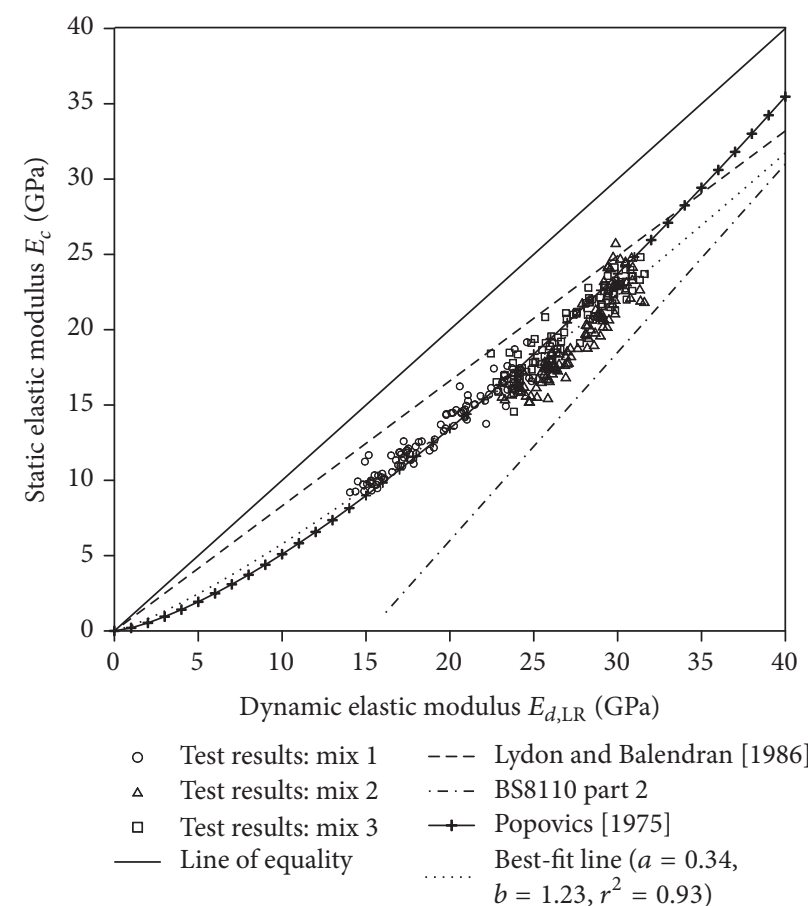

(a)

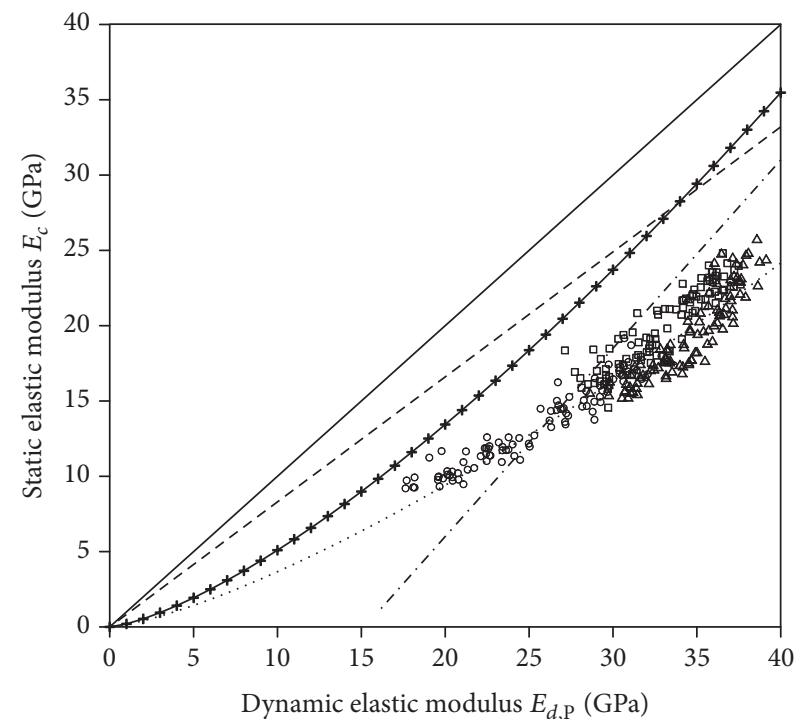

- Test results: mix $1 \quad$ - - Lydon and Balendran [1986]

$\triangle \quad$ Test results: $\operatorname{mix} 2 \quad$...- BS8110 part 2

口 Test results: mix $3 \multimap$ Popovics [1975]

- Line of equality Best-fit line $(a=0.16$, $\left.b=1.36, r^{2}=0.9\right)$

(c)

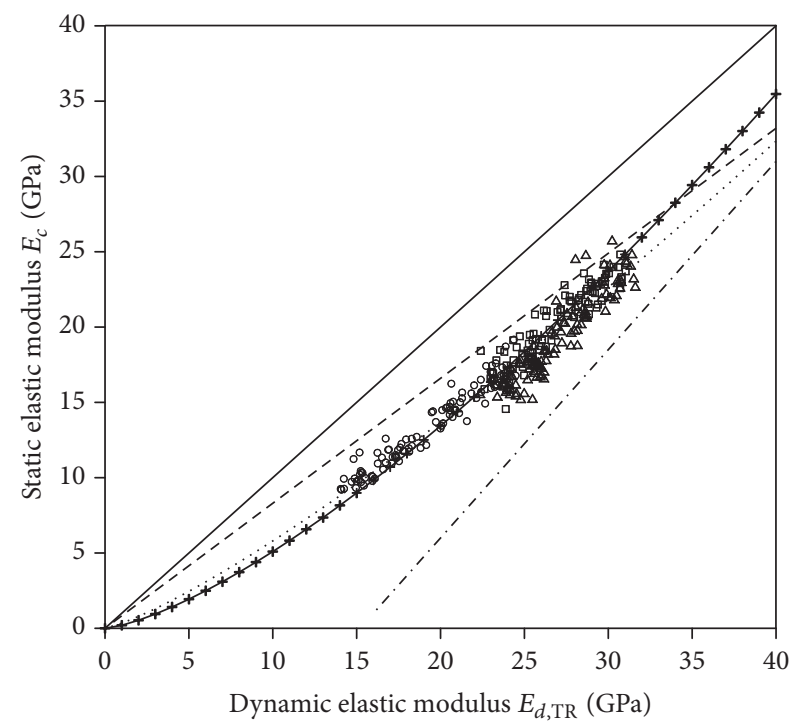

- Test results: mix $1 \quad$--- Lydon and Balendran [1986]

$\Delta \quad$ Test results: mix $2 \quad \ldots$ BS8110 part 2

口 Test results: mix $3 \rightarrow$ Popovics [1975]

— Line of equality ..... Best-fit line $(a=0.33$, $\left.b=1.24, r^{2}=0.93\right)$

(b)
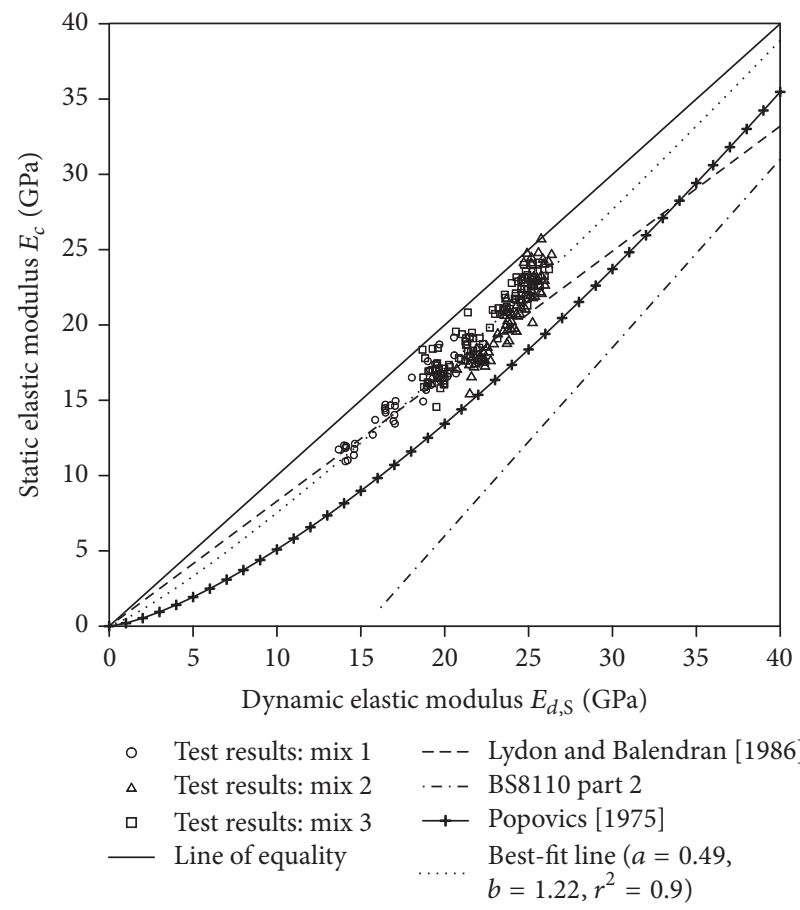

(d)

Figure 6: Relationship between static and dynamic elastic moduli: (a) $E_{c}$ versus $E_{d, \mathrm{LR}}$, (b) $E_{c}$ versus $E_{d, \mathrm{TR}}$, (c) $E_{c}$ versus $E_{d, \mathrm{P}}$, and (d) $E_{c}$ versus $E_{d, \mathrm{~S}}$.

domain. This phenomenon was substantial in observations of cylinders with relatively low compressive strength (i.e., mixes 1 and 2 at 4 days), and measured observations did not have a normal distribution. Therefore, those data sets were not included in the statistical analysis; special care is needed to measure the S-wave velocity of concrete having relatively low compressive strength.

3.2. Relationship between Static and Dynamic Elastic Moduli. Figure 6 presents the relationship between static and dynamic 
TABLE 3: Summary of constants $a$ and $b$ and $R^{2}$ for the best-fit lines in Figure 4 .

\begin{tabular}{lccc}
\hline Relationship & $a$ & $b$ & $R^{2}$ \\
\hline$E_{d, \mathrm{LR}}-E_{c}$ & 0.34 & 1.23 & 0.93 \\
$E_{d, \mathrm{TR}}-E_{c}$ & 0.33 & 1.24 & 0.93 \\
$E_{d, \mathrm{P}}-E_{c}$ & 0.16 & 1.36 & 0.90 \\
$E_{d, \mathrm{~S}}-E_{c}$ & 0.49 & 1.22 & 0.90 \\
\hline
\end{tabular}

Note. The basic form of the equation is $E_{c}=a E_{d}{ }^{b}$.

elastic modulus determined using different NDE methods, $E_{d, \mathrm{LR}}, E_{d, \mathrm{TR}}, E_{d, \mathrm{P}}$, and $E_{d, \mathrm{~S}}$, with an assumed Poisson's ratio of 0.2. The use of Poisson's ratio of 0.2 is reasonable for common concrete in practice [7]. The expression relating static to dynamic elastic modulus was obtained by nonlinear regression using the following power function relationship:

$$
E_{c}=a E_{d}^{b},
$$

where $E_{c}$ is the chord elastic modulus in GPa in accordance with ASTM C469/C460M-14 [6], $E_{d}$ is the dynamic elastic modulus in $\mathrm{GPa}$, and $a$ and $b$ are best-fit constants according to the regression analysis. It has been observed that the difference between static and dynamic elastic moduli decreases with increasing dynamic elastic modulus. Therefore, the nonlinear behavior was taken into account by using a power function. Furthermore, (13) results in zero static elastic modulus for zero dynamic elastic modulus. Table 3 summarizes the constants $a$ and $b$, and $R^{2}$ for the four bestfit curves, shown in Figure 6. For comparison, the same figure presents previously mentioned expressions ((1)-(3)) relating the static and dynamic elastic moduli of concrete. Table 4 summarizes mean absolute error (MAE) between the measured and the predicted static elastic modulus of concrete using the four best-fit curves proposed in this study and the three expressions ((1)-(3)).

The four dynamic moduli $\left(E_{d, \mathrm{LR}}, E_{d, \mathrm{TR}}, E_{d, \mathrm{P}}\right.$, and $\left.E_{d, \mathrm{~S}}\right)$ obtained from the resonant frequency tests and UPV method are greater than the static elastic modulus $E_{c}$ (see Figure 6). However, the ratios between static and dynamic elastic modulus vary according to the measurement methods. Figures 6(a) and $6(\mathrm{~b})$ show that the $E_{c} / E_{d, \mathrm{LR}}\left(\right.$ or $\left.E_{c} / E_{d, \mathrm{TR}}\right)$ ratio, with an average of 0.72 and COV of $7.15 \%$, was closer to the line of equality than $E_{c} / E_{d, \mathrm{P}}$. In the figure, the equation proposed by Lydon and Balendran [9] slightly overestimates $E_{c}$ from the two resonance moduli $\left(E_{d, \mathrm{LR}}\right.$ or $\left.E_{d, \mathrm{TR}}\right)$, with a mean absolute error (MAE) of $2.63 \mathrm{GPa}$. The equation proposed by the British Standard Institute [10] significantly underestimates $E_{c}$, with a MAE of 10.95 . In contrast, the equation proposed by Popovics [11] shows very good agreement with the experimental results in this study and appears to be effective for estimating a reasonably accurate $E_{c}$ from $E_{d, \mathrm{LR}}$ or $E_{d, \mathrm{TR}}$. However, as shown in Figure $6(\mathrm{c})$, the $E_{c} / E_{d, \mathrm{P}}$ ratio, with an average of 0.56 and COV of $9.2 \%$, is too far away from the line of equality as well as from the three proposed equations relating static and dynamic elastic modulus.

Figure $6(\mathrm{~d})$ shows that the ratio $E_{c} / E_{d, \mathrm{~S}}$, with an average of 0.87 and $\mathrm{COV}$ of $6.2 \%$, was even closer to the line of equality than $E_{c} / E_{d, \mathrm{LR}}$ (or $E_{c} / E_{d, \mathrm{TR}}$ ). The equations proposed by

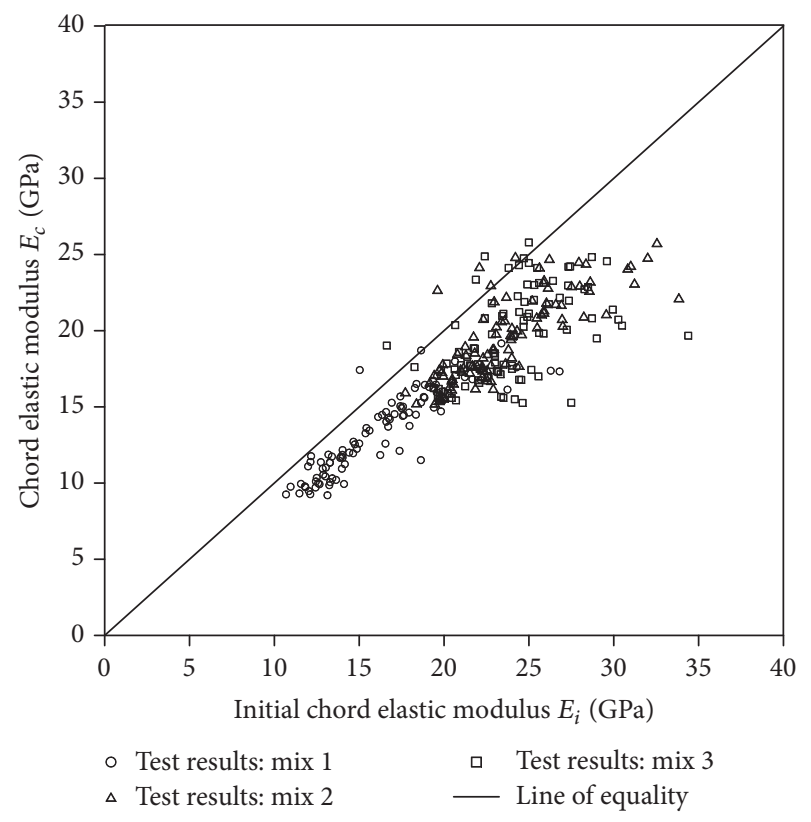

FIGURE 7: Relationship between initial chord modulus and standard chord modulus.

British Standard Institute and Popovics resulted in relatively high MAE of $6.36 \mathrm{GPa}$ and $3.76 \mathrm{GPa}$, respectively. However, the best-fit curve obtained in this study and the equation suggested by Lydon and Balendran [9] shows good agreement with the experimental results in this study, with a relatively low MAE of 0.82 and $1.19 \mathrm{GPa}$, respectively. Therefore, the two equations could be a good candidate as a practical formula relating $E_{d, \mathrm{~S}}$ and $E_{c}$ with reasonable accuracy for normal concrete with similar mixture proportions in this study.

3.3. Relationship between Initial Chord and Dynamic Elastic Moduli. Figure 7 shows the relationship between the initial chord modulus and the standard chord modulus. The majority of the data points indicate that the initial chord modulus is greater than the standard chord modulus. This implies that the nonlinear stress-strain behavior of concrete is one of the possible reasons for differences between static and dynamic elastic modulus. It has been believed that the dynamic elastic modulus represents the tangent elastic modulus (or initial chord modulus in this study) at low strain [7]. Therefore, it is of some interest to compare dynamic elastic modulus to initial chord modulus to better understand the nonlinearity effect. 


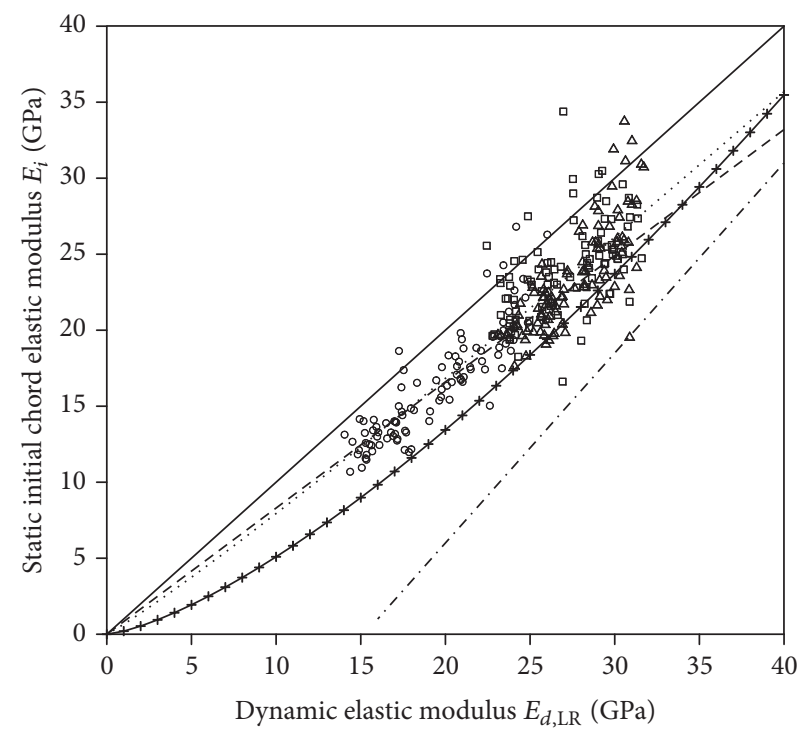

- Test results: mix $1 \quad$ - -- Lydon and Balendran [1986]

$\Delta \quad$ Test results: $\operatorname{mix} 2 \quad \ldots$ BS8110 part 2

口 Test results: mix $3 \longrightarrow$ Popovics [1975]

— Line of equality _..... Best-fit line $(a=0.65$, $\left.b=1.08, r^{2}=0.78\right)$

(a)

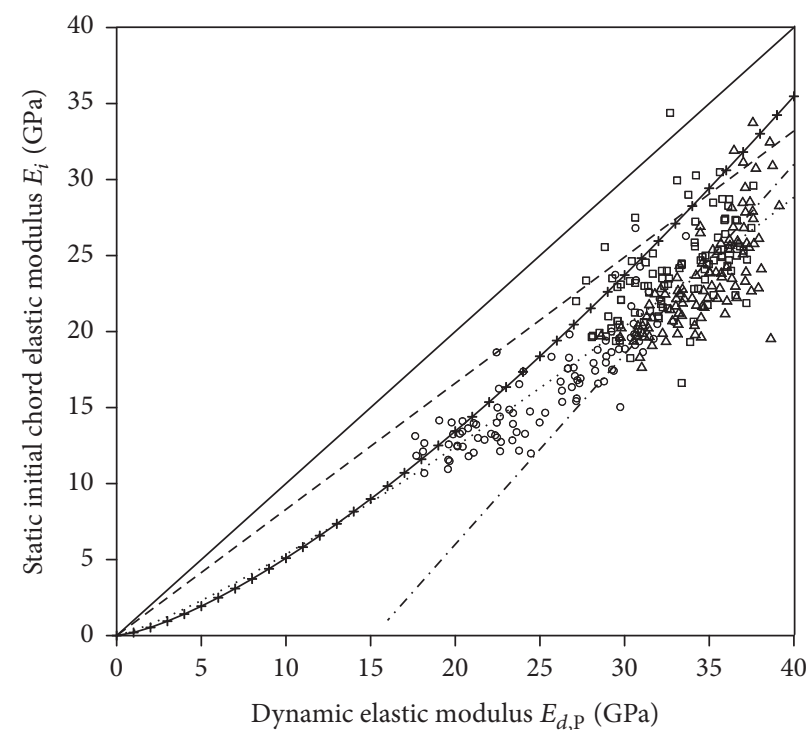

○ Test results: mix 1

$\triangle \quad$ Test results: $\operatorname{mix} 2$

口 Test results: mix 3

_ Line of equality

-- - Lydon and Balendran [1986]

-.- BS8110 part 2

$\rightarrow$ Popovics [1975]

Best-fit line $(a=0.32$, $\left.b=1.21, r^{2}=0.75\right)$

(c)

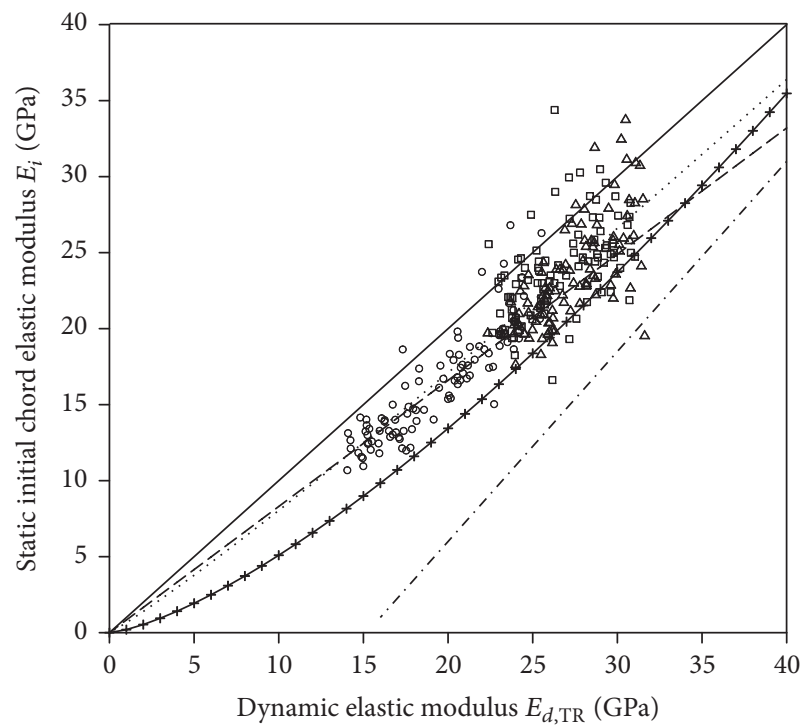

- Test results: mix $1 \quad$ - - - Lydon and Balendran [1986]

$\triangle \quad$ Test results: mix $2 \quad \ldots$ BS8110 part 2

口 Test results: mix $3 \quad \longrightarrow$ Popovics [1975]

— Line of equality _..... Best-fit line $(a=0.65$, $\left.b=1.08, r^{2}=0.77\right)$

(b)

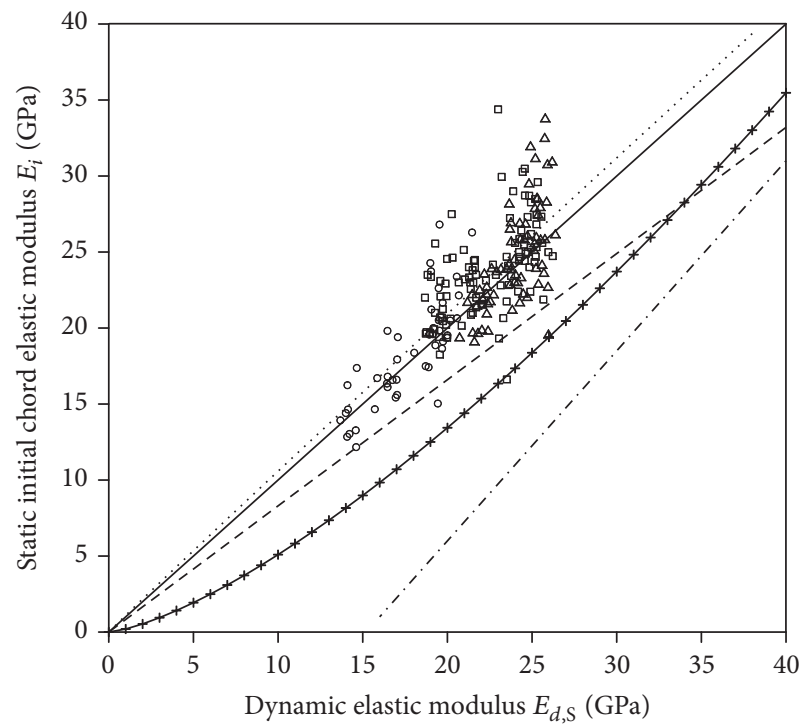

(d)

...- BS8110 part 2

+ Popovics [1975]

Best-fit line $(a=1.09$, $b=0.98, r^{2}=0.72$ )

FIGURE 8: Relationship between initial chord and dynamic elastic moduli: (a) $E_{i}$ versus $E_{d, \mathrm{LR}}$, (b) $E_{i}$ versus $E_{d, \mathrm{TR}}$, (c) $E_{i}$ versus $E_{d, \mathrm{P}}$, and (d) $E_{i}$ versus $E_{d, s}$.

Figures $8(a)-8(d)$ compare the initial chord and dynamic elastic moduli from different methods. As expected, the difference between initial chord and dynamic elastic moduli is smaller than that between standard static and dynamic moduli. Note that more scatter in Figure $8, E_{i}$ and $E_{d}$ relation, than in Figure 6, $E_{c}$ and $E_{d}$ relation, is attributable to some fluctuating data measured in a low strain level for calculating $E_{i}$.

Figure $8(\mathrm{~d})$ shows that $E_{d, \mathrm{~S}}$ is close to the line of equality, with an average $E_{i} / E_{d, S}$ ratio of 1.04 and COV of $11.0 \%$. 
TABLE 4: Mean absolute error (MAE) of expressions relating static and dynamic elastic modulus.

\begin{tabular}{|c|c|c|c|c|}
\hline \multirow{2}{*}{ Equation converting $E_{d}$ into $E_{c}$} & \multicolumn{4}{|c|}{ MAE (GPa) } \\
\hline & $E_{d, \mathrm{P}}$ & $E_{d, \mathrm{~S}}$ & $E_{d, \mathrm{LR}}$ & $E_{d, \mathrm{TR}}$ \\
\hline Line of equality & 13.38 & 2.78 & 7.06 & 6.76 \\
\hline (1) (Lydon and Balendran [9]) & 8.11 & 1.19 & 2.87 & 2.63 \\
\hline (2) (British Standard Institute [10]) & 19.24 & 6.36 & 11.33 & 10.95 \\
\hline (3) (Popovics [11]) & 7.41 & 3.76 & 1.11 & 0.97 \\
\hline Best-fit line & 1.05 & 0.82 & 0.84 & 0.85 \\
\hline
\end{tabular}

Note. MAE is mean absolute error $(=\Sigma|Y-\widehat{Y}| / N$, where $Y$ is the predicted values using the three proposed equations and $\widehat{Y}$ is the measured values and $N$ is the number of specimens).

Therefore, the difference between static and dynamic elastic modulus of $E_{d, \mathrm{~S}}$ is mainly attributed to the nonlinear stressstrain curve of concrete up to $40 \%$ of compressive strength. In contrast, resonance dynamic moduli $\left(E_{d, \mathrm{LR}}\right.$ and $\left.E_{d, \mathrm{TR}}\right)$, shown in Figures 8(a) and 8(b), still show considerable difference from $E_{i}$. Furthermore, $E_{d, \mathrm{P}}$ shown in Figure $8(\mathrm{c})$ is considerably higher than $E_{i}$. It seems that there are other influential factors causing differences between static and dynamic elastic modulus for $E_{d, \mathrm{P}}$ and the two resonance moduli $\left(E_{d, \mathrm{LR}}\right.$ and $\left.E_{d, \mathrm{TR}}\right)$.

It has been suggested that differences between static and dynamic elastic moduli are attributable to the fact that the nonhomogeneous characteristics of concrete affect the two moduli in different ways $[7,8]$. The static modulus of concrete has been demonstrated to be more dependent on the elastic properties of the paste, whereas, for P-wave velocity, the elastic modulus of the aggregates is the more influential factor. In normal-weight concrete, the elastic modulus of aggregates is generally greater than the paste, providing a reason for higher dynamic modulus compared to the static modulus. Similarly, the nonhomogeneity of concrete appears to affect the fundamental resonance frequencies of concrete cylinders. In contrast, the S-wave velocity method is likely the least sensitive to the heterogeneity of concrete. However, additional experimental data are needed to confirm this hypothesis due to the limited quantity of experimental data in this study and scarcity of experimental studies exploring the relationship between static modulus and dynamic elastic modulus based on S-wave measurements.

3.4. Relationship between Compressive Strength and Dynamic Elastic Modulus. The plot in Figure 9 represents the relationship between static elastic modulus and compressive strength measured in accordance with ASTM C469/C469M-14 [6] and ASTM C39/C39M-14 [18], respectively. Figure 9 also compares the experimental results with code equations [3336] and a recently proposed equation by Noguchi et al. [37]. The CEB-FIP and Eurocode 2 link elastic modulus $E_{c}$ to compressive strength $f_{c}\left(E=22000\left(f_{c} / 10\right)^{1 / 3}\right.$ in MPa $)$ for both normal-strength and high-strength concrete. ACI proposes two different equations: $E=0.043\left(f_{c}\right)^{1 / 2}(w)^{1.5} \mathrm{MPa}$ for $\left(f_{c} \leq\right.$ $38 \mathrm{MPa})$ by the ACI 318 committee and $E=\left(3320\left(f_{c} / 10\right)^{1 / 2}+\right.$ $6900)(w / 2300)^{1.5} \mathrm{MPa}$ for $\left(21 \mathrm{MPa}<f_{c}<83 \mathrm{MPa}\right)$ by the

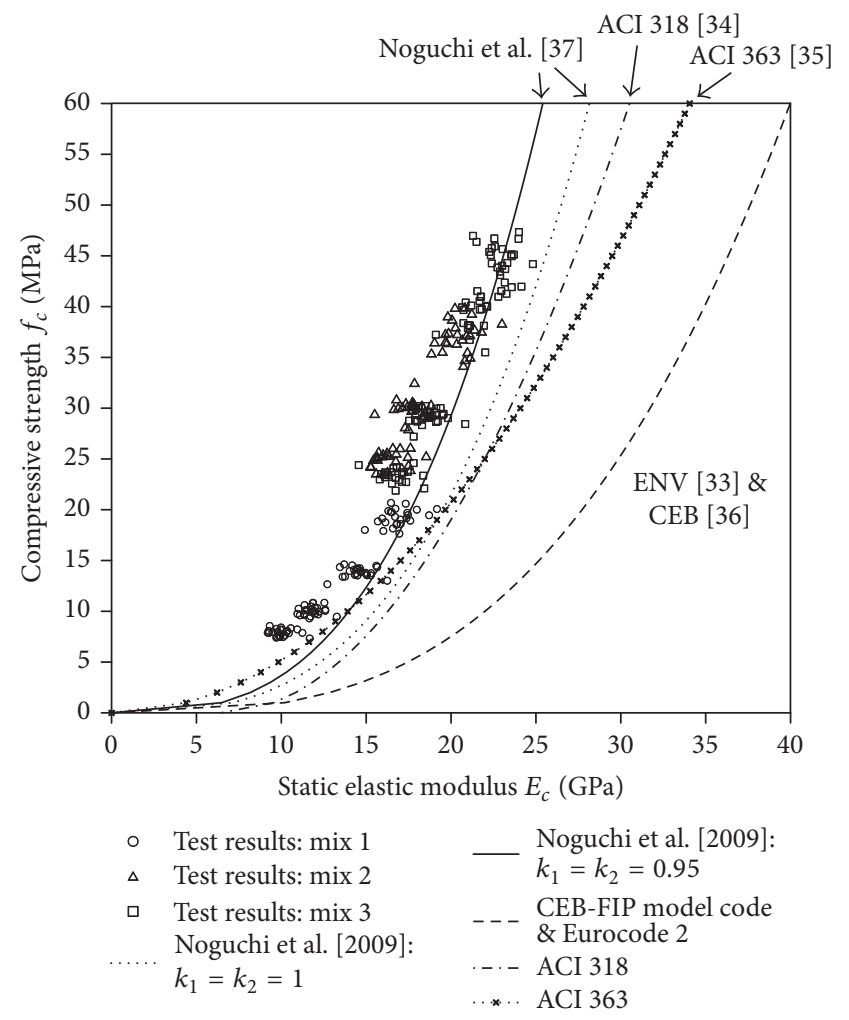

FIGURE 9: Relationship between compressive strength $f_{c}$ and static elastic modulus $E_{c}$.

ACI 363 committee. Noguchi et al. [37] proposed a practical equation based on an extensive experimental database including normal-strength and high-strength concrete: $E=$ $k_{1} k_{2} 33500\left(f_{c} / 60\right)^{1 / 3}(w / 2400)^{2}$, where $k_{1}$ and $k_{2}$ are correction factors for coarse aggregates and SCMs. Figure 9 shows that the three code equations significantly underestimate compressive strength, which is mainly due to the fact that some critical factors (e.g., the types of coarse aggregates and SCMs) have not been properly taken into account in the code equations. However, the Noguchi equation [37] predicts experimental results with greatly improved accuracy by using correction factors $k_{1}=k_{2}=0.95$.

Figure 10 compares measured and predicted compressive strength based on different equations relating static and 


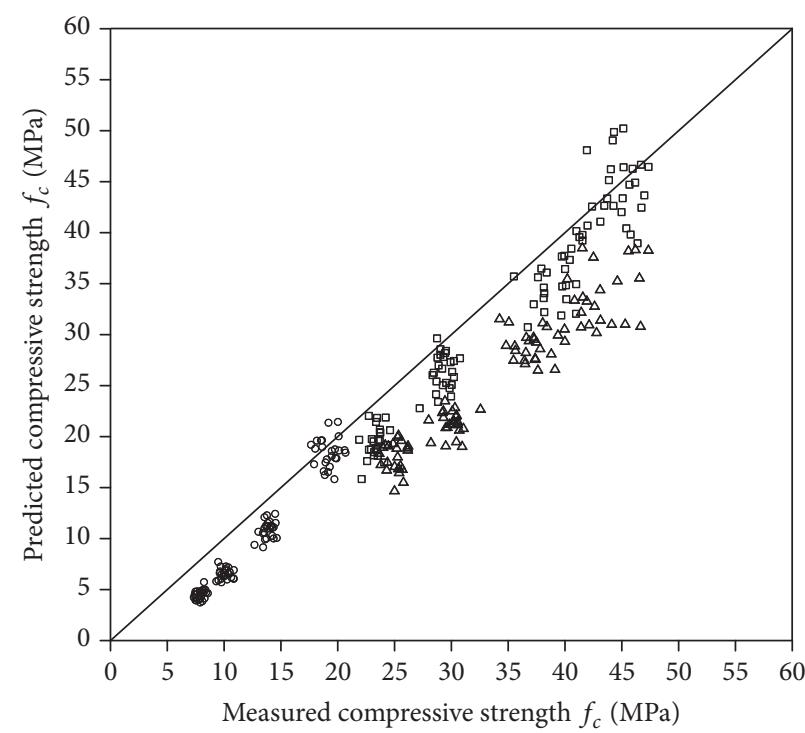

- Test results: mix 1

$\Delta$ Test results: $\operatorname{mix} 2$

ㅁ Test results: mix 3

_ Line of equality

(a)

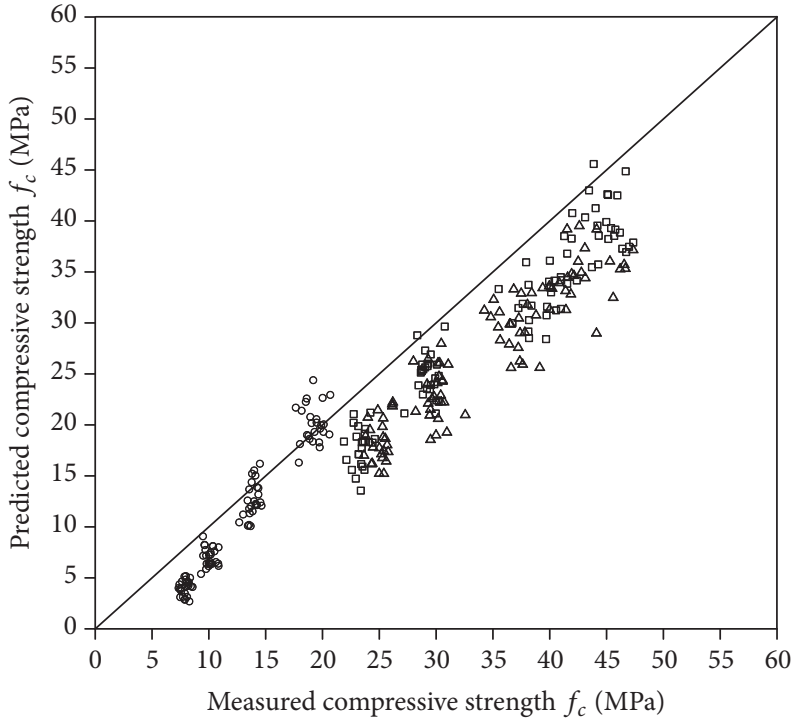

- Test results: mix 1

$\Delta$ Test results: mix 2

口 $\quad$ Test results: mix 3

_ Line of equality

(c)

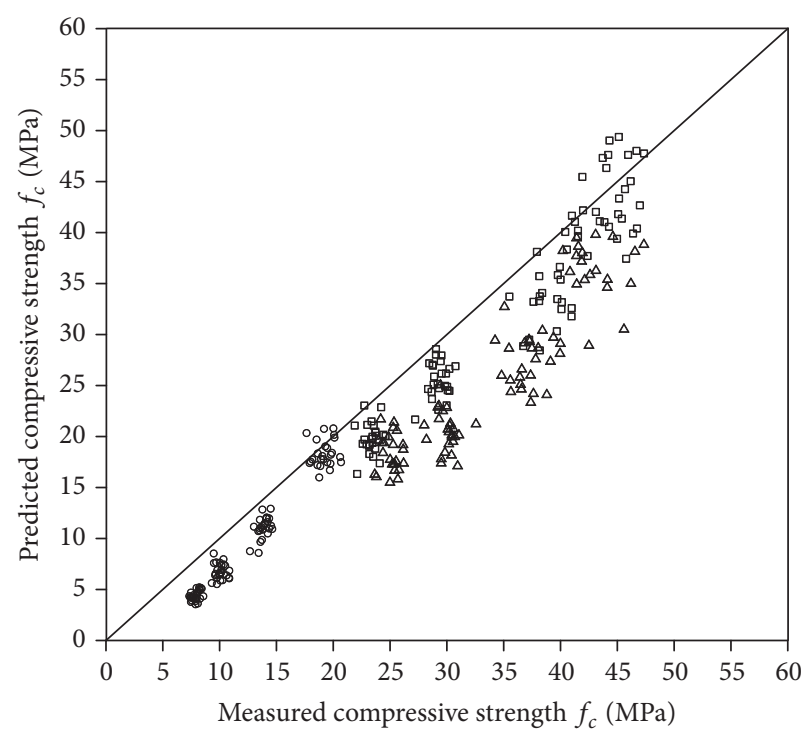

- Test results: mix 1

$\Delta$ Test results: mix 2

$\quad$ Test results: mix 3

_ Line of equality

(b)

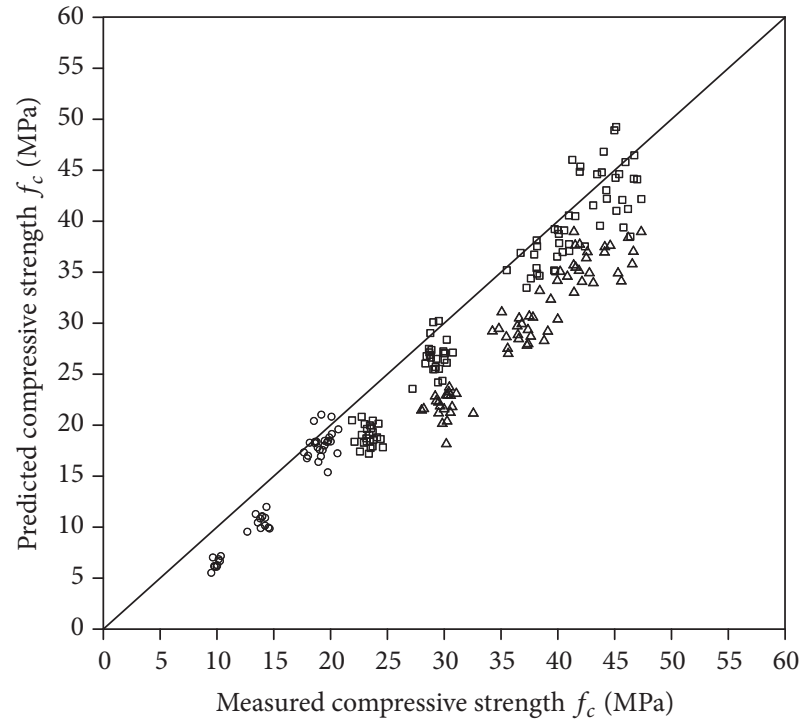

- Test results: mix 1

ㅁ Test results: $\operatorname{mix} 3$

$\Delta$ Test results: mix 2

(d)

FIGURE 10: Relationship between predicted and measured compressive strength determined from various dynamic moduli: (a) $E_{d, \mathrm{LR}}$, (b) $E_{d, \mathrm{TR}}$, (c) $E_{d, \mathrm{P}}$, and (d) $E_{d, \mathrm{~s}}$.

dynamic elastic modulus. The Noguchi equation [37] was used to correlate compressive strength and dynamic elastic modulus as follows:

$$
f_{c}=\eta\left(E_{c}\right)^{3}=\eta\left(a E_{d}^{b}\right)^{3},
$$

where $f_{c}$ is estimated concrete strength, $\eta=60(\mathrm{w} /$ $2400)^{-3 / 2}\left(k_{1} k_{2} 33500\right)^{-3}$, and $a$ and $b$ are constants depending on equations relating static and dynamic elastic modulus (see Table 3). Figure 10 shows that the proposed equation
(14) slightly underestimates the compressive strength of concrete when converting dynamic into static elastic modulus using the best-fit curves. The MAEs between measured and estimated values using $E_{d, \mathrm{P}}, E_{d, \mathrm{~S}}, E_{d, \mathrm{LR}}$, and $E_{d, \mathrm{TR}}$ are $4.9,4.2,4.3$, and $4.3 \mathrm{MPa}$, respectively. However, it was observed in Figure 10 that the predicted compressive strength is linearly correlated with measured compressive strength, and the plots are consistently biased toward underestimation of the compressive strength. Consequently, it was found that the proposed equation (14) could improve the accuracy of 
predicted compressive strength through a simple calibration process of adding a certain correction factor: MAE values would be a good candidate for a simple calibration factor. Therefore, it can be concluded that the predetermined equations relating dynamic to static elastic modulus, summarized in Table 4, are effective for estimating compressive strength within reasonable errors.

\section{Conclusions}

An experimental study was conducted to explore the relationship between static and dynamic elastic moduli using ultrasonic pulse velocity methods and resonance tests and to demonstrate the potential of the S-wave velocity method as an in situ dynamic elastic modulus evaluation method in practice. Conclusions are drawn as follows:

(1) It was demonstrated that the coefficient of variation (COV) of the S-wave shows very good repeatability. It is as good as P-wave velocity measurements and comparable to resonance tests. The average $\mathrm{COV}$ of the S-wave velocity $\left(C_{S}\right)$ is $0.97 \%$; the average COV of P-wave velocity $\left(C_{\mathrm{P}}\right)$ is $1.38 \%$; the average $\mathrm{COV}$ of resonant frequency measurements are $1.19 \%$ and $1.35 \%$ for longitudinal and transverse resonance frequencies, respectively.

(2) The four dynamic moduli $\left(E_{d, \mathrm{LR}}, E_{d, \mathrm{TR}}, E_{d, \mathrm{P}}\right.$, and $\left.E_{d, \mathrm{~S}}\right)$ obtained from the resonance frequency and ultrasonic pulse velocity (UPV) tests are greater than the static elastic modulus $E_{c}$. Test results from this study and the literature show that the best-fit curve and the equation suggested by Popovics [11] ((3) in this study) are effective for predicting static elastic moduli from resonance moduli of concrete, with MAEs of 1.0 and 1.2 GPa, respectively. For velocity moduli from Swave velocity measurements, the best-fit curve and the equation suggested by Lydon and Balendran [9] ((1) in this study) show good agreement with the experimental results in this study, with MAEs of $0.82 \mathrm{GPa}$ and $1.19 \mathrm{GPa}$, respectively. However, velocity modulus from $\mathrm{P}$-wave measurements is excessively greater then static elastic modulus. The empirical equations (see (1), (2), and (3)) result in significant errors between the static and dynamic moduli, with $\mathrm{MAE}$ in a range of $7.41 \mathrm{GPa}$ to $19.24 \mathrm{GPa}$.

(3) $E_{d, \mathrm{~S}}$ was observed to be almost linearly correlated with $E_{i}$, with a mean absolute error of $2 \mathrm{GPa}$. Therefore, it can be concluded that the difference between the initial elastic modulus of concrete and $E_{d, \mathrm{~S}}$ is mainly attributable to the nonlinear stress-strain curve of concrete. In contrast, resonance dynamic moduli $\left(E_{d, \mathrm{LR}}\right.$ and $\left.E_{d, \mathrm{TR}}\right)$ are slightly higher than the initial tangent modulus of concrete $E_{i}$. Moreover, $E_{d, \mathrm{P}}$ is considerably higher than $E_{i}$. There should be other influential factors (such as heterogeneity of concrete) causing differences between static and dynamic elastic modulus for the P-wave modulus $\left(E_{d, \mathrm{P}}\right)$ and the two resonance moduli $\left(E_{d, \mathrm{LR}}\right.$ and $\left.E_{d, \mathrm{TR}}\right)$.
(4) With an established equation between static and dynamic elastic modulus, the dynamic elastic modulus can be used to estimate the compressive strength of cylinders. It is demonstrated that the predetermined equations relating dynamic to static elastic modulus are effective for estimating compressive strength within reasonable errors.

\section{Conflicts of Interest}

The authors declare that there are no conflicts of interest regarding the publication of this manuscript.

\section{Acknowledgments}

This research was supported by Basic Science Research Program through the National Research Foundation of Korea (NRF) funded by the Ministry of Science, ICT \& Future Planning (no. 2015R1A5A1037548).

\section{References}

[1] J. S. Popovics, "A study of static and dynamic modulus of elasticity of concrete," in ACI-CRC Final Report, 2008.

[2] P. K. Mehta and P. J. M. Monteiro, Concrete-Microstructure, Properties, and Materials, McGraw-Hill, 3rd edition, 1993.

[3] ASTM C666/C666M-15, Standard Test Method for Resistance of Concrete to Rapid Freezing and Thawing, West Conshohoken, $\mathrm{Pa}$, USA, 2015.

[4] ASTM C597/C597M-16, Standard Test Method for Pulse Velocity through Concrete, West Conshohoken, Pa, USA, 2016.

[5] ASTM C215-14, Standard Test Method for Fundamental Transverse, Longitudinal, and Torsional Resonant Frequencies of Concrete Specimens, West Conshohoken, Pa, USA, 2016.

[6] C469 A, Standard Test Method for Static Modulus of Elasticity and Poisson's Ratio of Concrete in Compression, West Conshohoken, Pa, USA, 2014.

[7] A. M. Neville, Properties of Concrete, John Wiley \& Sons, New York, NY, USA, 4th edition, 1997.

[8] R. E. Philleo, "Comparison of results of three methods for determining Young's modulus of elasticity of concrete," Journal of the Americal Concrete Institute, vol. 26, no. 5, pp. 461-469, 1955.

[9] F. D. Lydon and R. V. Balendran, "Some observations on elastic properties of plain concrete," Cement and Concrete Research, vol. 16, no. 3, pp. 314-324, 1986.

[10] British Standard Institute., Structural Use of Concrete-Part 2: Code of Practice for Special Circumstance. BS 8110-2:1995, BSI, London, UK, 1985.

[11] S. Popovics, "Verification of relationships between mechanical properties of concrete-like materials," Matériaux and Constructions, vol. 8, no. 3, pp. 183-191, 1975.

[12] K. F. Graff, Wave Motion in Elastic Solids, Dover publications, INC., New York, NY, USA, 4th edition, 1991.

[13] M. Cha and G.-C. Cho, "Compression wave velocity of cylindrical rock specimens: engineering modulus interpretation," The Japan Society of Applied Physics, vol. 46, no. 7B, pp. 4497-4499, 2007.

[14] B. J. Lee, S.-H. Kee, T. Oh, and Y.-Y. Kim, "Effect of cylinder size on the modulus of elasticity and compressive strength of 
concrete from static and dynamic tests," Advances in Materials Science and Engineering, vol. 2015, Article ID 580638, 12 pages, 2015.

[15] T. Voigt, G. Ye, Z. Sun, S. P. Shah, and K. Van Breugel, "Early age microstructure of Portland cement mortar investigated by ultrasonic shear waves and numerical simulation," Cement and Concrete Research, vol. 35, no. 5, pp. 858-866, 2005.

[16] J. Zhu, S.-H. Kee, D. Han, and Y.-T. Tsai, "Effects of air voids on ultrasonic wave propagation in early age cement pasets," Cement and Concrete Research, vol. 41, no. 8, pp. 872-881, 2011.

[17] S. Liu, J. Zhu, S. Seraj, R. Cano, and M. Juenger, "Monitoring setting and hardening process of mortar and concrete using ultrasonic shear waves," Construction and Building Materials, vol. 72, pp. 248-255, 2014.

[18] J. Carette and S. Staquet, "Monitoring the setting process of mortars by ultrasonic P and S-wave transmission velocity measurement," Construction and Building Materials, vol. 94, pp. 196208, 2015.

[19] J. An, J. Nam, S. Kwon, and S. Joh, "Estimation of the compressive strength of concrete using shear wave velocity," in Proceedings of the GeoHunan International Conference, Changsha, China, 2009.

[20] D. Ciancio and M. Helinski, "The use of shear wave velocity for assessing strength development in fibre reinforced shortcrete," in Proceeding of the 3rd International Conference on Engineering Developments in Shotcrete, CRC Press, Queenstown, New Zealand, 2010.

[21] U. Lencis, A. Udris, and A. Korjakins, "Decrease of the ultrasonic pulse velocity in concrete caused by reinforcement," Journal of Materials Science and Engineering, vol. 1, pp. 10161028, 2011.

[22] A. A. Samokrutov, V. N. Kozlov, and V. G. Shevaldkin, "Ultrasonic low-frequency transdcers with dry dot contact and their applications for evaluation of concrete structures," in Proceeding of the 8th European Conference on Nondestructive Testing Conference (ECNDT '02), Barcelona, Spain, June 2002.

[23] Y. H. Lee and T. Oh, "The measurement of P-, S-, and R-wave velocities to evaluate the condition of reinforced and prestressed concrete slabs," Advances in Materials Science and Engineering, vol. 2016, Article ID 1548215, 14 pages, 2016.

[24] A. O. De La Haza, A. A. Samokrutov, and P. A. Samokrutov, "Assessment of concrete structures using the Mira and Eyecon ultrasonic shear wave devices and the SAFT-C image reconstruction technique," Construction and Building Materials, vol. 38, pp. 1276-1291, 2013.

[25] ASTM C31/C31M-12, Standard Practice for Making and Curing Concrete Test Specimen in the Field, West Conshohoken, Pa, USA, 2012.

[26] ASTM C39/C39M-14 A, Standard Test Method for Compressive Strength of Cylindrical Concrete Specimens, West Conshohoken, $\mathrm{Pa}, \mathrm{USA}, 2014$.

[27] A. Alam and L. Haselbach, "Estimating the modulus of elasticity of pervious concrete based on porosity," Advances in Civil Engineering Materials, vol. 3, no. 1, pp. 257-269, 2014.

[28] J. S. Popovics and etal., "One-sided stress wave velocity measurement in concrete," Journal of Engineering Mechanics-Asce, vol. 124, no. 12, pp. 1346-1353, 1998.

[29] J. Lin and M. Sansalone, "A procedure for determining Pwave speed in concrete for use in impact-echo testing using a Rayleigh wave speed measurement technique," in Innovations in Nondestructive Testing of Concrete, SP-168, E. S. Pessiki and L. Olson, Eds., pp. 137-165, American Concrete Institute, Farmington Hills, Mich, USA, 1997.

[30] V. Barnett and T. Lewis, Outliers in Statistical Data, John Wiley \& Sons, New York, NY, USA, 1994.

[31] ACI committee 214, Guide for Evaluation of Strength Test Results of Concrete (ACI 214R-11), Farmington Hills, Mich, USA, American Concrete Institute, 2011.

[32] ACI committee 228, "Nondestructive test methods for evaluation of concrete in structures," Report ACI 228.2R-98, American Concrete Institute, Farmington Hills, Mich, USA, 1998.

[33] ENV 1992-1-1, Eurocode 2. Design of Concrete Structures-Part 1: General Rules and Rules for Buildings, 2004.

[34] ACI committee 318, Building Code Requirements for Structural Concrete (ACI 318-14) and Commentary, 2014.

[35] ACI committee 363, "State-of-the-art report on high-strength concrete," ACI Journal Proceedings, vol. 84, no. 4, pp. 364-411, 1984.

[36] Comité Euro-International du Béton, "High-performance concrete, recommended extensions to the model code 90-research needs,' CEB Bulletin d'Information, p. 46, 1995.

[37] T. Noguchi, F. Tomosawa, K. M. Nemati, B. M. Chiaia, and A. P. Fantilli, "A practical equation for elastic modulus of concrete," ACI Materials journal, vol. 106, no. 5, pp. 690-696, 2009. 

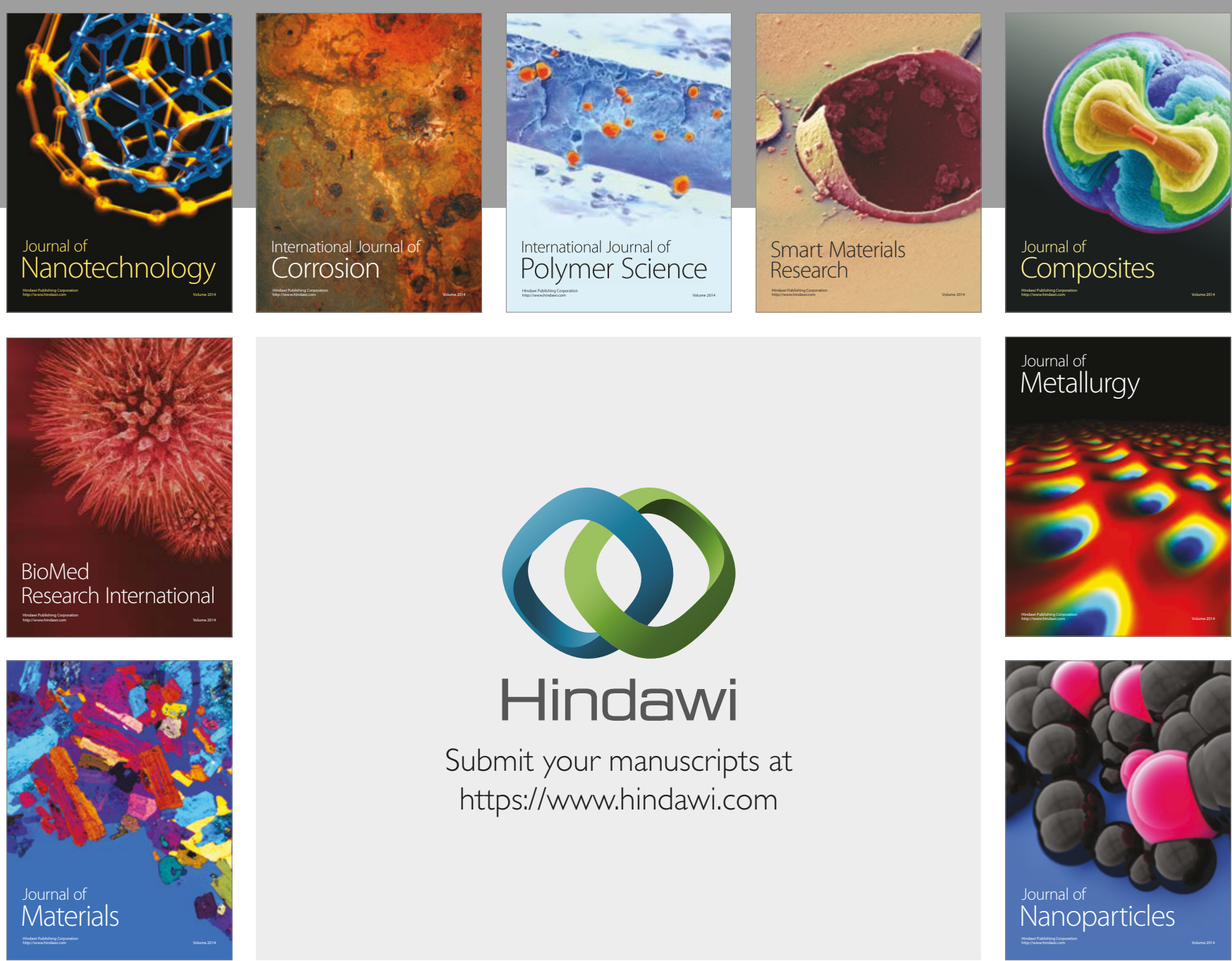

\section{Hindawi}

Submit your manuscripts at

https://www.hindawi.com
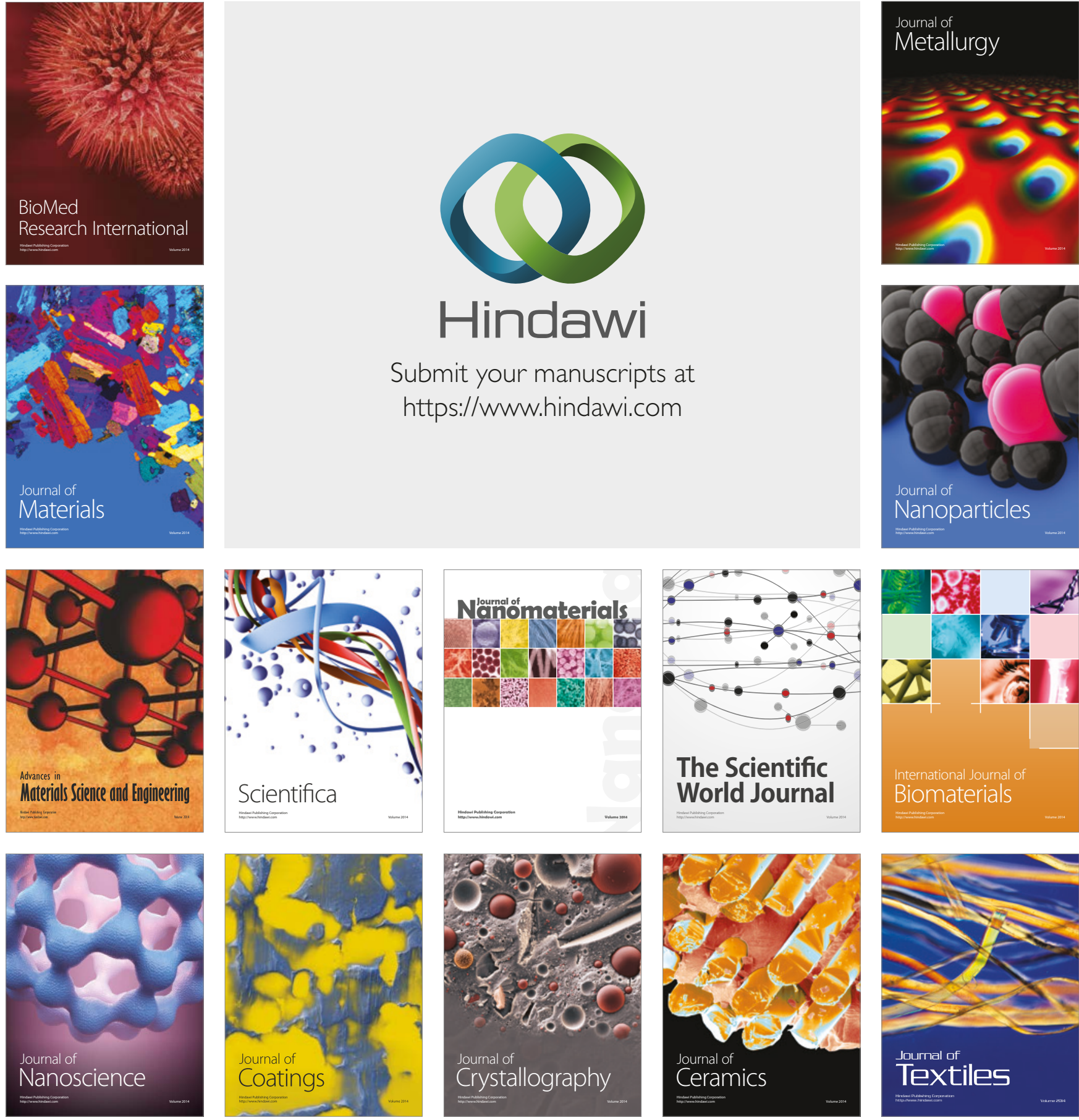

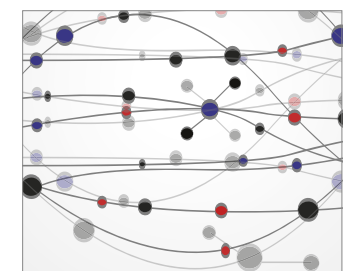

The Scientific World Journal
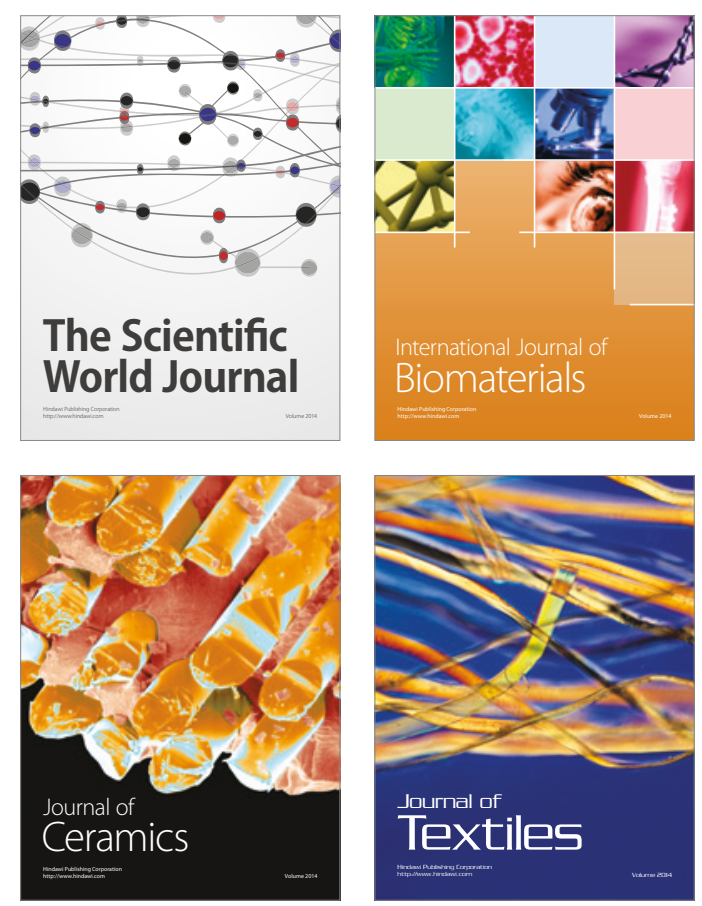